This reciprocal appearance of type $A$ or type $B$ will continue without special ratios in successive generations. It can be influenced by natural or artificial selection. After many generations of selection in one direction, there is produced an assortment of modifiers of the same type, and the observed character becomes pseudo-dominant.

The Galton Laboratory,

$$
\text { T. M. OLBRycht. }
$$

Rothamsted Experimental Station, Harpenden, Herts.

Dec. 7.

1 NATURE, 145, 390 (1940).

\section{Immunity from Cellular Changes in the Blood}

Cumulative evidence from a series of investigations on Past. pestis (1,2,3 $^{1,}$ specially in relation to active, passive and natural immunity and bactericidal tests in vitro and in vivo, strongly suggested that the humoral factors could only be partly responsible for host resistance against a highly invasive organism like the plague bacillus.

During the course of studies on the cellular reactivity to plague infection it was observed that certain types of changes took place in the white cells of blood which, when studied by the supravital technique as described by Sabin and her collaborators ${ }^{4,5,6}$, were found to be indicative of $(a)$ active immunity, (b) passive immunity, and $(c)$ susceptibility on the part of the experimental animal.

Bombay rats were employed for the study of active immunity since they are partially immune to plague infection, and a certain percentage of them always survived the test infective dose. Haffkine Institute inbred white mice, which have been shown to be most susceptible to plague?, were used as controls as well as for passive protection tests. It was possible to study the cellular changes for a number of days in the same animal by bleeding it from the tail every morning and afternoon.

Both active and passive immunity were associated with the presence in the blood stream of those cells which have been variously described as clasmatocytes ${ }^{8}$, histiocytes ${ }^{9}$, and as wandering endothelial phagocytes ${ }^{5}$.

(1) In active immunity there was a constant 'shower' of clasmatocytes which, along with an increase in the total number of leucocytes and abnormal functional activity on their part, indicated that the animal was going to survive. On the other hand, where, in a partially immune animal, the plague infection was going to prove fatal, the percentage of clasmatocytes was low and they were present for the first 48-72 hours only; the functional activity of both the monocytes and the granulocytes was below normal and the neutrophils gradually lost their motility and became rounded. Towards the end, the white blood cells presented a typical moth-eaten 'ground glass' appearance without vacuoles or granules. This picture always connoted a very grave prognosis and invariably ended fatally.

(2) In a susceptible animal, like the white mouse, no clasmatocytes were seen at any stage of infection. From the cellular point of view the animal took a downhill course almost from the very start. All the signs associated with grave prognosis developed by about the fourth day, and in spite of a total white cell count of 40-50,000 per c.mm., and a monocytic percentage as high as 25 , the animal succumbed to infection on the fifth to seventh day.

(3) In passive immunity the presence of clasmatocytes was directly related to the envelope antibodythe protective component of an anti-plague serum ${ }^{10}$. There was, however, a threshold value below which the clasmatocytic cellular reaction was not observed. Above the threshold value the percentage of clasmato. cytes and the duration of their presence in the blood stream depended on the amount of the envelope anti. body administered.

The somatic component of an anti-plague serum, which in animal experiments was devoid of any protective value ${ }^{3}$, was never found to be associated with the appearance of clasmatocytes in the blood stream.

The details of this investigation are being communicated elsewhere.

Haffkine Institute, Bombay.

Nov. 7.

1 Bhatnagar, S. S., Ind. J. Med. Res., 28, 1 (1940).

2 Bhatnagar, S. S., ibid., 28, 16 (1940).

Bhatnagar, S. S., Shrivastava, D. I., and Kamat, G. K., ibid. (in the Press).

- Sabin, F. R., Bull. Johns Hopkins., 34, 277 (1923).

S Sabin, F. R., Doan, C. A., and Cunningham, R. S., Contrib. Embryology, Carnegie Inst. Wash. Pub., 16, 127 (1925).

- Cunningham, R. S., Sabin, F. R., and Doan, C. A., ibid., 16, 227 (1925).

'Sokhey, S. S., Ind. J. Med. Res., 27, 341 (1939).

${ }^{8}$ Ranvier, C.R. Acad. Sci., April 20, p. 842 (1891).

- Aschoff, L., Kiyono, K., Folia Hamatol., 15, 383 (1913).

${ }^{10}$ Schütze, H., Brit. J. Exp. Path., 15, 200 (1934).

\section{Pigments of Iris pseudacorus}

A NUMBER of blue and purple varieties of the Iris family have been included in their "Survey of Anthocyanins" by G. M. and R. Robinson, who have specified the particular anthocyanidin present in each case. They have found, for example, that Iris miranda. ${ }^{1}$ contains a complex delphinidin diglycoside and that a malvidin 3:5 dimonoside mixed with what is probably a petunidin derivative is present in Iris Kompferii ${ }^{2}$.

On the other hand, Iris pseudacorus, commonly known as the water-flag, owes its colour to the presence of carotinoids, a fact which was first established by van Wisselingh ${ }^{3}$ from a cursory examination of the flowers by means of colour reactions.

We are at present engaged on a detailed investigation of the nature of the carotinoids present in Iris pseudacorus. We have succeeded in resolving the very complex mixture of pigments present into five different fractions. B-Carotene is present, and from the mixture of other pigments, which are xanthophylls, violaxanthin and lutein have been isolated and characterized. Whilst these constitute the major portion of the xanthophyll fraction, spectroscopic evidence disclosed the presence in very small amounts of what is probably zeaxanthin. In addition, a dark red wax-like substance, with absorption bands in carbon disulphide at 496, 465 and $436 \mu \mu$, was isolated. Kuhn and Winterstein ${ }^{4}$ in their examination of the carotinoids of Viola tricolor obtained an unidentified coloured waxy product which had the same 